\title{
The validity and reliability of the CAMDEX-DS for assessing dementia in adults with Down syndrome in Brazil
}

\author{
Luciana M. Fonseca, ${ }^{1,2}$ iD Glenda G. Haddad, ${ }^{1}$ Guilherme P. Mattar, ${ }^{1}$ Melaine C. de Oliveira, ${ }^{3}$ \\ Sharon S. Simon, ${ }^{1}$ Laura M. Guilhoto, ${ }^{4,5}$ Geraldo F. Busatto, ${ }^{1,6}$ Shahid Zaman, ${ }^{2}$ Anthony J. Holland, ${ }^{2}$ \\ Marcelo Q. Hoexter, ${ }^{7}$ Cassio M. Bottino ${ }^{1}$ \\ ${ }^{1}$ Programa Terceira Idade (PROTER), Departamento e Instituto de Psiquiatria, Hospital das Clínicas, Faculdade de Medicina, Universidade de \\ São Paulo (USP), SP, Brazil. ${ }^{2}$ Cambridge Intellectual and Developmental Disabilities Research Group, Department of Psychiatry, University of \\ Cambridge, Cambridge, UK. ${ }^{3}$ Department of Statistics, Florida State University, Tallahassee, FL, USA. ${ }^{4}$ Associação de Pais e Amigos dos \\ Excepcionais de São Paulo (APAESP), São Paulo, SP, Brazil. ${ }^{5}$ Departamento de Neurologia e Neurocirurgia, Universidade Federal de São \\ Paulo (UNIFESP), São Paulo, SP, Brazil. ${ }^{6}$ Laboratório de Neuroimagem em Psiquiatria (LIM 21), Departamento e Instituto de Psiquiatria, \\ Hospital das Clínicas, Faculdade de Medicina, USP, São Paulo, SP, Brazil. ${ }^{7}$ Projeto Transtornos do Espectro Obsessivo-Compulsivo \\ (PROTOC), Departamento e Instituto de Psiquiatria, Hospital das Clínicas, Faculdade de Medicina, USP, São Paulo, SP, Brazil. \\ (iD https://orcid.org/0000-0002-2849-0545
}

\begin{abstract}
Objective: Alzheimer's disease occurs at a higher prevalence and an earlier age in individuals with Down syndrome (DS) than typically developing individuals. However, diagnosing dementia in individuals with intellectual disability remains a challenge due to pre-existing cognitive deficits. The aim of this study was to investigate the validity and reliability of the Brazilian version of the Cambridge Examination for Mental Disorders of Older People with Down's syndrome and Others with Intellectual Disabilities (CAMDEX-DS) for individuals with DS.

Methods: Two psychiatrists, working independently, evaluated 92 adults with DS $\geqslant 30$ years of age. The concurrent validity of the CAMDEX-DS was analyzed in relation to the gold standard of established international criteria. In a subgroup of 20 subjects, the concurrent validity of the CAMDEX-DS was analyzed in relation to an independent objective assessment of cognitive decline over three years. We analyzed the inter-rater reliability of cognitive assessment.

Results: The diagnostic accuracy of the CAMDEX-DS compared to the gold standard was $96.7 \%$. CAMDEX-DS-based diagnosis was considered consistent with cognitive decline. The probability of a participant with dementia having cognitive decline was $83 \%$. Inter-rater reliability for the participant assessment was good, with a kappa of $>0.8$ for $93 \%$ of the CAMDEX-DS items.

Conclusion: The CAMDEX-DS can be considered the first valid and reliable instrument for evaluating dementia in adults with DS in Brazil. Its use in such individuals could improve clinical practice and research.
\end{abstract}

Keywords: Alzheimer disease; Down syndrome; diagnosis; dementia; intellectual disability

\section{Introduction}

Down syndrome (DS) is a chromosomal anomaly caused by the presence of an extra copy of chromosome $21 .^{1}$ There are no official estimates of the prevalence and incidence of DS in Brazil. However, in a collaborative study involving 129 maternity hospitals in nine South American countries (including Brazil), the live birth prevalence rate of DS between 1995 and 2012 was reported as $0.12 \%{ }^{2}$ The estimated live birth prevalence of DS in the United States was approximately $0.14 \%$ between 2004 and $2006 .^{3}$ In England, the live birth prevalence of DS in 2010 was approximately $0.10 \%, 54 \%$ less than expected due

Correspondence: Luciana Mascarenhas Fonseca, Programa Terceira Idade, Instituto de Psiquiatria, Hospital das Clínicas, Faculdade de Medicina, Universidade de São Paulo, Rua Dr. Ovídio de Campos, 785, Cerqueira Cesar, CEP 05403-010, São Paulo, SP, Brazil.

E-mail: Imfonseca@usp.br

Submitted Jan 24 2018, accepted May 07 2018, Epub Oct 222018. to screening programs and consequent abortions. ${ }^{4}$ The characteristics of DS can include the physical phenotype (hypotonia, short stature, protruding tongue, and flattened facial appearance) and the clinical presentation of neuropsychological developmental delay that results in intellectual disability in most individuals with DS.

There is a genetic link between DS and the early development of neuropathological features of Alzheimer's disease (AD) during adult life. ${ }^{5}$ That association is explained in part by the extra copy of chromosome 21 , a chromosome linked to the overexpression of certain proteins related to the neurodegeneration process, including the protein precursor of $\beta$-amyloid in the brain and superoxide

How to cite this article: Fonseca LM, Haddad GG, Mattar GP, de Oliveira MC, Simon SS, Guilhoto LM, et al. The validity and reliability of the CAMDEX-DS for assessing dementia in adults with Down syndrome in Brazil. Braz J Psychiatry. 2019;41:225-233. http://dx. doi.org/10.1590/1516-4446-2018-0033 
dismutase $1 .^{6}$ Thus, the triplicate copy of chromosome 21 leads to higher levels of proteins related to $A D$ in DS brains. In addition, DS is associated with premature structural brain aging. ${ }^{7}$ Post-mortem studies have shown that virtually all individuals with DS show neuropathological signs of $A D$ after reaching 40 years of age, including senile plaques containing $\beta$-amyloid and neurofibrillary tangles. ${ }^{5}$ Because of the pathological similarity of $A D$ among individuals with DS, research in this population has great potential to advance understanding of $A D$ in the general population. Neuroimaging studies have demonstrated $\beta$-amyloid deposition in individuals $\geqslant 40$ years of age with DS, appearing first in the striatum, followed by prefrontalcingulo-parietal areas, ${ }^{8}$ and occurring prior to the onset of dementia. ${ }^{9}$ However, the psychiatric and neuropsychological features of the symptomatology of $A D$ in $D S$ can be considerably different than those expected for the general population. $^{10}$

The specificities of the progression of $A D$ in individuals with DS, together with the presence of previous cognitive deficits attributed to intellectual disability, make the diagnosis of dementia in this population challenging. It requires diagnostic assessment procedures that incorrate the specific information necessary to enable an accurate clinical diagnosis. Instruments used to detect cognitive decline in the general population are not suitable for individuals with DS, because they are based on studies of individuals with typical intellectual development and have not been adapted for use in individuals with a low basal level of cognitive and functional abilities. Although several instruments have been developed or adapted for this population in Europe and the United States, ${ }^{11-14}$ none have been translated to Portuguese or validated for use in Brazil. Consequently, there are no instruments available for diagnosing dementia in individuals with DS in Brazil. The Cambridge Examination for Mental Disorders of Older People with Down's syndrome and Others with Intellectual Disabilities $(C A M D E X-D S)^{11}$ is a diagnostic instrument consisting of an objective neuropsychological assessment of the individual with DS (CAMCOG-DS) and a detailed interview to be conducted with an informant, which allows a decline from the individual's best level of functioning to be established. ${ }^{15}$ The CAMDEX-DS is designed to provide support for good clinical and research practices. In a review including an analysis of instruments used in recent years, ${ }^{10}$ the CAMDEX-DS was the only diagnostic assessment tool that was based on standardized international criteria, was designed for use in individuals with intellectual disability and $A D$, is administered to an informant, and includes a direct cognitive assessment of the subject. The CAMDEXDS was found to be one of the most widely used instruments in studies in this area. In this paper, we report on the validity and reliability of the CAMDEX-DS for diagnosing dementia in a population of individuals with DS in Brazil.

\section{Methods}

\section{Ethics}

The study was approved by the research ethics committee of the Hospital das Clínicas, Universidade de São Paulo
(USP), and was registered with the national committee for ethics in research through Plataforma Brasil (CAAE no. 37381414.8.0000.0065).

\section{Study design}

This was a cross-sectional, case-control study with longitudinal analysis for a subgroup of participants.

\section{Setting}

The study was carried out by the Programa Terceira Idade (PROTER) of the Instituto de Psiquiatria, Hospital das Clínicas, Faculdade de Medicina, USP, in partnership with the Associação de Pais e Amigos dos Excepcionais de São Paulo (APAESP) and the Associação para o Desenvolvimento Integral do Down (ADID). Assessments were performed at the hospital or at one of the involved associations, depending on the logistics (i.e., the most convenient location for the participants and their families). In some cases, when a participant's or informant's mobility was limited, parts of the evaluations were performed in their home. In all cases, the assessments were carried out in silent rooms arranged for the evaluation. When the assessments were divided over testing sessions, the time between them was 1 or 2 weeks at most.

\section{Participants}

All participants met the ICD-10 criteria for a diagnosis of DS (code, Q90) and were $\geqslant 30$ years of age. The majority of the participants were or had previously been enrolled in APAESP or ADID. Eight additional individuals were included in the study after meeting participants. APAESP and ADID identified eligible participants and provided a list of contacts. The objectives of the study were explained to all participants in a simple, concrete manner, and any questions or concerns had were addressed. Due to their intellectual disability, written informed consent was obtained not only from the participants, but their legal guardians as well. Figure 1 illustrates the process of selecting subjects for inclusion in the study.

\section{CAMDEX-DS}

The CAMDEX-DS ${ }^{11}$ is a version of the CAMDEX scale, ${ }^{16}$ modified and adapted for DS, that incorporates the specific information necessary to enable an accurate clinical diagnosis and to facilitate the differential diagnosis of any observed decline in this population. It takes into account pre-morbid difficulties, establishing decline from the individual's best level of functioning. The CAMDEX-DS includes informant and participant interviews with objective assessment of cognitive function, as well as a standardized schedule for recording observations, physical examination findings, and laboratory test results. The domains covered in the CAMDEX-DS informant interview are: Participant's Best Level of Functioning (education and employment, basic skills, and independent living); Cognitive and Functional Decline (everyday skills, memory, orientation, general mental functioning, language, perception, 


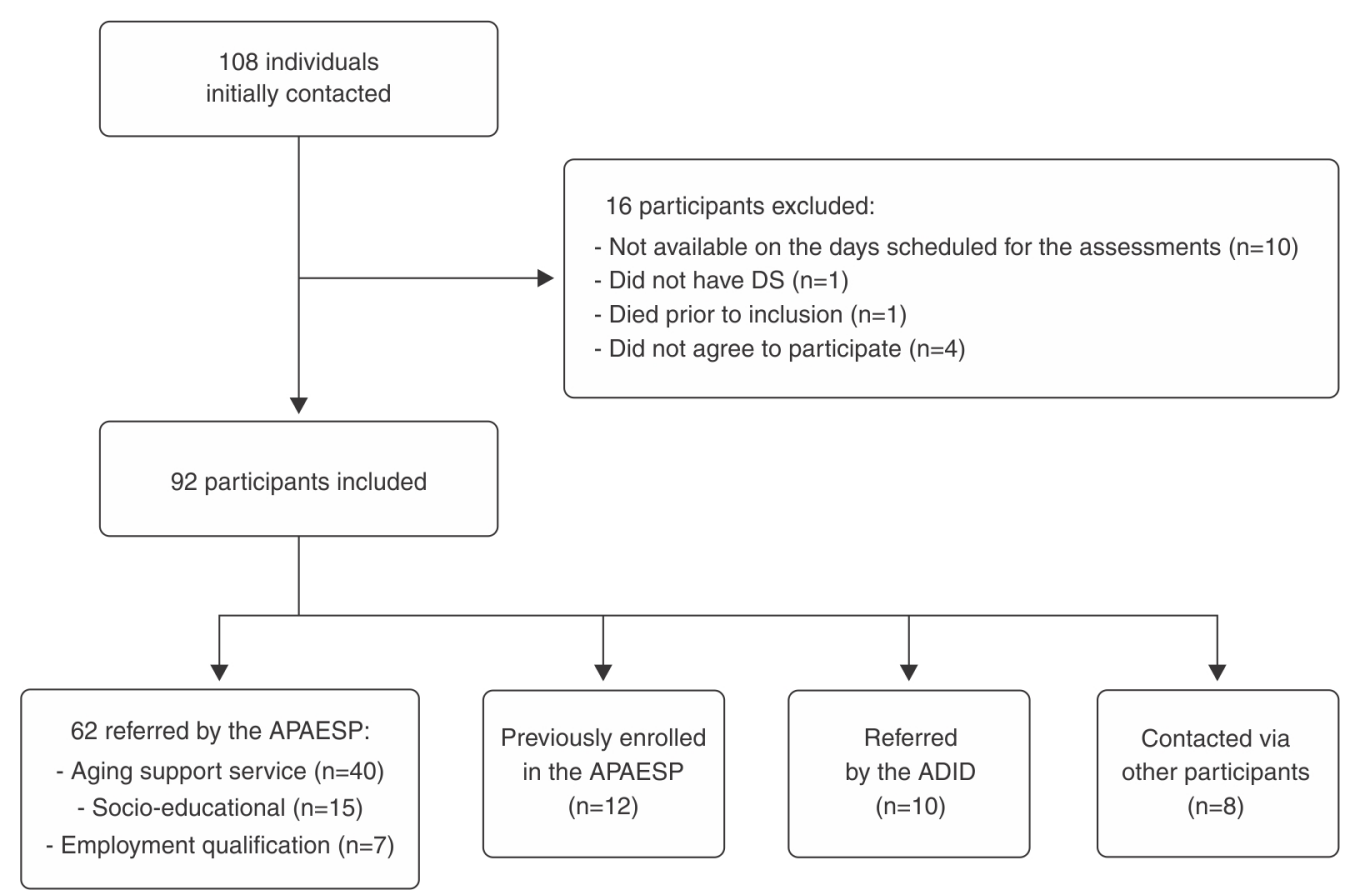

Figure 1 Flow chart of the participant inclusion process. ADID = Associação para o Desenvolvimento Integral do Down; APAESP = Associação de Pais e Amigos dos Excepcionais de São Paulo; DS = Down syndrome.

praxis, executive functions, personality, behavior, and self-care); Current Mental Health (depression, anxiety, paranoid illness, clouding/ delirium, and substance abuse); and Current Physical Health (physical disability, hypothyroidism, cerebrovascular problems, other physical illness, and medication).

Bottino et al. translated the CAMDEX to Portuguese and culturally adapted and validated it for use in Brazilian adults from the typically developing population with dementia. ${ }^{17}$ The reliability of the syndromic diagnosis of dementia, as determined by calculating the kappa statistic $(\kappa)$, was excellent $(\kappa=0.94)$ and that of the etiological diagnosis was good $(\kappa=0.83)$, both with a $p$-value of 0.001 . In Brazil, the Portuguese-language version of the CAMDEX has shown good applicability and is widely used by clinicians and researchers. ${ }^{18-20}$

The original CAMDEX-DS validation study involved 74 individuals $\geqslant 30$ years of age with $D S$ in England. ${ }^{11}$ For diagnosing $A D$, the CAMDEX-DS showed a specificity of 0.94 and a sensitivity of 0.88 . The inter-rater reliability was considered good $(\kappa>0.8)$ for $91 \%$ of the items and fair $(\kappa>0.6)$ for all of the items collectively. The CAMDEX-DS has also been validated for use in Spain. ${ }^{21}$ It is now widely used in studies of individuals with DS and intellectual disability. ${ }^{7,8,22,23}$

\section{CAMCOG-DS}

The Cambridge Cognitive Examination adapted for individuals with Down Syndrome (CAMCOG-DS) is a concise group of neuropsychological tests included in the CAMDEX-DS. It was designed to ensure that most individuals with DS score above the test floor, thus improving the detection of cognitive decline. Some questions from the original CAMCOG were removed after proving to have a high floor effect; in other CAMCOG-DS questions, the participant can acquire a half-score because the interviewer is allowed to provide clues as needed. The CAMCOG-DS comprises subscales for the following domains: orientation; language (comprehension and expression); memory (new learning, remote, and recent); attention; praxis (drawing complex figures and the ability to carry out complex tasks); abstract thinking; and perception. The maximum total score on the CAMCOG-DS is 109 points.

Hon et al. ${ }^{24}$ showed that the CAMCOG can differentiate between older and younger individuals with DS. The authors concluded that, with minor modifications, the CAMCOG is a useful test for evaluating areas of cognitive function that are known to deteriorate in dementia. In addition, the decline in CAMCOG scores was greater in participants who had been diagnosed with dementia than in those who had not.

The CAMCOG-DS is a reference for studies investigating cognitive processes in adults with intellectual disability. ${ }^{23,25-27}$ In one study of individuals with DS in Brazil, a longitudinal comparison of individual performance on the CAMCOG was found to enrich the analysis of cognitive decline. ${ }^{28}$

Translation and cultural adaptation of the CAMDEX-DS for use in Brazip9

The content validation of the CAMDEX-DS involved the following steps: initial translation to Portuguese; cultural adaptation with assistance of a multidisciplinary team 
assembled from the PROTER Research Group; evaluation of the cognitive portion of the translated, adapted version for equivalence (semantic, idiomatic, conceptual, and experimental) and comprehension by two neuropsychologists, working independently; suggestions made by the two neuropsychologists; re-adaptation taking those suggestions into account; re-evaluation of the new version; back-translation into the original English by a free-lance bilingual translator with no access to the original version; evaluation (by the original authors) of the equivalence of the modified cognitive portion; and a pilot test involving 10 adults with DS who did not participate in the subsequent validation study. The pilot was considered comprehensive, requiring no further modifications.

\section{Diagnostic categories}

We established three diagnostic categories: AD, prodromal dementia, and stable cognition. Prodromal dementia was defined as evidence of cognitive decline that was more severe than that expected for the stable cognition group, but not severe enough to meet the criteria for AD. The categories were established separately based on the CAMDEX-DS guidelines and the gold standard.

\section{Diagnostic assessment using the CAMDEX-DS}

The CAMDEX-DS questionnaire was administered by a trained psychiatrist who made the diagnosis based on the CAMDEX-DS guidelines and the CAMCOG-DS results, but was blinded to all other assessments and information. CAMDEX inclusion criteria for AD indicate a decline in: a) everyday skills; b) memory; and c) one of the following: general mental functioning, language, praxis, object recognition, executive function, and/or personality and behavior. The duration of the changes must be greater than six months with gradual onset and no evidence of clouding/delirium, signs of vascular dementia, or secondary dementia. The time required to administer the CAMDEX-DS questionnaire to the informant varied from 40 to 60 minutes.

\section{Gold standard diagnostic procedure}

A psychiatrist trained in geriatrics and intellectual disability performed the gold standard diagnostic evaluation. Because of the challenge of using a gold standard for diagnosing dementia in individuals with DS in Brazil, the evaluation was based on criteria established in the Diagnostic Manual - Intellectual Disability, ${ }^{30}$ the DSM $-5^{31}$ and the ICD $-10,{ }^{32}$ with the rater blinded to the CAMDEX-DS-based diagnosis. In addition to a structured clinical interview, the rating psychiatrist applied the Informant Questionnaire on Cognitive Decline in the Elderly, ${ }^{33}$ the Neuropsychiatric Inventory, ${ }^{34}$ and the Frontal System Behavior Scale. ${ }^{35}$ The rater also had access to neuropsychological assessment data other than the CAMCOG score, as well as to all available medical records. The time required for the gold standard diagnosis varied from 90 minutes to 120 minutes.

\section{Neuropsychological assessment}

A neuropsychologist applied the CAMCOG-DS and the Wechsler Abbreviated Scale of Intelligence. ${ }^{36}$ The total time required to apply the instruments varied from 90 minutes to 120 minutes. When necessary, the evaluation was divided into two sessions with a maximum of 1 week between them.

\section{Concurrent validity between the CAMDEX-DS and the gold standard}

The concurrent validity between the CAMDEX-DS and the gold standard clinical diagnostic procedure was established through the agreement level of diagnoses made by each method.

\section{Concurrent validity between the CAMDEX-DS and objective assessment of cognitive decline over 3 years}

We examined the concurrent validity between the CAMDEX-DS and an objective assessment of cognitive decline for 20 subjects in our sample who had participated in a previous longitudinal study by our team involving the CAMCOG. ${ }^{28}$ The second CAMCOG assessment was performed when the CAMDEX-DS was applied. Cognitive decline was defined as one standard deviation (SD) below the mean change in CAMCOG score. ${ }^{11}$

\section{Inter-rater reliability of the CAMCOG-DS}

For the inter-rater reliability analysis of the CAMCOG-DS, the responses of 20 individuals with DS were rated simuItaneously and independently by the neuropsychologist who conducted the cognitive assessment and a psychiatrist who observed the assessment. The results of the items and subscales were compared for each participant.

\section{Statistical analysis}

To determine the concurrent validity between the gold standard diagnosis and the CAMDEX-DS-based diagnosis, we calculated type I errors, type II errors, sensitivity, specificity, accuracy, predictive value, and the likelihood ratio. We also analyzed the agreement between the two variables by calculating the kappa statistic. To determine inter-rater reliability, the level of agreement between the interviewers was also analyzed by calculating the kappa statistic. To analyze the concurrent validity between the CAMDEX-DS-based diagnosis and the cognitive decline assessment, we compared the groups' 95\% confidence intervals $(95 \% \mathrm{Cl})$ for cognitive decline, crosstabulated the data, performed Fisher's exact test, and calculated the odds ratio (OR). For the sample as a whole, assumptions of homogeneity of demographic features among groups (stable cognition vs. prodromal dementia vs. AD) were verified with the Kruskal-Wallis test (for continuous variables) or Fisher's exact test (for categorical variables). The level of statistical significance was set at $p<0.05$. All selected data were tabulated with the 
Research Electronic Data Capture (REDCap) program ${ }^{37}$ and analyzed with SPSS version 14.

\section{Results}

\section{Demographic data}

Table 1 shows the demographic characteristics of the sample as a whole, as well as comparisons among the groups. The overall prevalence of $A D$ was $11.9 \%$, whereas that of prodromal dementia was $19.6 \%$ (based on the gold standard).

All informants had known the participant for at least 10 years, and the majority were family members or primary caregivers. We found that there were considerably more primary caregivers who were not the parents in the prodromal dementia and $A D$ groups than in the stable cognition group.

\section{Concurrent validity between the CAMDEX-DS and the gold standard}

The analysis of concurrent validity between CAMDEX-DS and the gold standard included 92 individuals. Compared to the gold standard, the CAMDEX-DS had a specificity for dementia (proportion of individuals accurately identified as having no dementia) of $98.4 \%$ and a sensitivity for $A D$ (proportion of individuals accurately identified as having $A D$ ) of $100 \%$. In addition, the CAMDEX-DS had a sensitivity of $88.9 \%$ for diagnosing prodromal dementia.
Therefore, the overall accuracy of the CAMDEX-DS was $96.7 \%$, i.e., the proportion of true positives and true negatives among all evaluated cases (Table 2). The predictive value or precision (ratio of true positives to combined true and false positives) of the CAMDEX-DS-based AD diagnosis in this sample of individuals $\geqslant 30$ years of age with DS was $84.6 \%$, whereas it was $94.1 \%$ for the CAMDEX-DSbased prodromal dementia diagnosis. The kappa statistic for the agreement between the CAMDEX-DS and the gold standard was $0.93(p<0.05)$.

\section{Concurrent validity between CAMDEX-DS and cognitive decline over three years}

The CAMDEX-DS-based diagnosis was cross-tabulated with a decline in CAMCOG scores over a 3-year period in a subgroup of 20 participants. At baseline, none of them was diagnosed with dementia. Of those 20 participants, $12(60 \%)$ were male. The mean age of the participants was 47.8 years (SD 6.81), ranging from 39 to 60 years. Those whose CAMCOG score declined $>5.8$ points - at least $1 \mathrm{SD}$ (9.38) from the mean change for the group $(-3.5)$ - were significantly more likely to be diagnosed with $A D$ or prodromal dementia ( $p=0.049$, Fisher's exact test). Of the 11 participants in the stable cognition group, only one $(9.1 \%)$ showed such a decline. Among the six participants diagnosed with prodromal dementia, the CAMCOG score declined by $>5.8$ points in two $(33.3 \%)$, by $<5.8$ points in two (33.3\%), and improved overall by 3 points in two (33.3\%). The CAMCOG score of all three

Table 1 Demographic and clinical characteristics of the participants

\begin{tabular}{|c|c|c|c|c|c|}
\hline Characteristic & $\begin{array}{l}\text { Sample as a whole } \\
\qquad(\mathrm{n}=92)\end{array}$ & $\begin{array}{l}\text { Stable cognition } \\
\qquad(\mathrm{n}=63)\end{array}$ & $\begin{array}{l}\text { Prodromal dementia } \\
\qquad(n=18)\end{array}$ & $\underset{(n=11)}{A D}$ & $p$-value* \\
\hline Age (years), mean (SD) & $42.45(8.51)$ & $38.84(7.43)$ & $44.89(6.22)$ & $53.36(8.13)$ & $<0.001$ \\
\hline Maternal age at birth (years), mean (SD) & $34.18(7.70)$ & $33.27(7.42)$ & $34.18(9.28)$ & $39.80(4.21)$ & 0.092 \\
\hline Intellectual disability ${ }^{\dagger}$ & & & & & 0.009 \\
\hline Mild & $34(37.8)$ & $28(44.4)$ & $4(23.5)$ & $2(20.0)$ & \\
\hline Moderate & $34(37.8)$ & $24(38.1)$ & 9 (52.9) & $1(10.0)$ & \\
\hline Severe & $22(24.4)$ & $11(17.5)$ & $4(23.5)$ & $7(70.0)$ & \\
\hline Male, gender & $59(64.1)$ & $41(65.1)$ & $10(55.6)$ & $8(72.7)$ & 0.632 \\
\hline Education & & & & & 0.261 \\
\hline None & $8(8.7)$ & $4(6.3)$ & $4(22.2)$ & $0(0)$ & \\
\hline Specialized school & $60(65.2)$ & $40(63.5)$ & $11(61.1)$ & $9(81.8)$ & \\
\hline Specialized and regular school & $21(22.8)$ & $17(27.0)$ & $2(11.1)$ & $2(18.2)$ & \\
\hline Regular school & $3(3.3)$ & $2(3.2)$ & $1(5.6)$ & $0(0)$ & \\
\hline Relationship with informant & & & & & 0.009 \\
\hline Parent & $53(57.6)$ & $42(66.7)$ & $9(50.0)$ & $2(18.2)$ & \\
\hline Sibling or other & $39(42.4)$ & 21 (33.3) & $9(50.0)$ & $9(81.8)$ & \\
\hline Hypothyroidism & $48(75.0)$ & $30(47.6)$ & $13(72.2)$ & $5(45.4)$ & 0.160 \\
\hline Epilepsy & $13(20.3)$ & $7(11.1)$ & $2(11.1)$ & 4 (36.3) & 0.082 \\
\hline Sedentary life style & $36(39.1)$ & $19(30.2)$ & $9(50.0)$ & $8(72.7)$ & 0.017 \\
\hline Medication that affects the CNS & $20(21.7)$ & 9 (14.3) & $4(22.2)$ & $7(63.6)$ & 0.002 \\
\hline Family history of $A D$ & $23(25.0)$ & $12(19.0)$ & $5(27.8)$ & $6(54.5)$ & 0.044 \\
\hline
\end{tabular}

Data presented as $\mathrm{n}(\%)$, unless otherwise specified.

$\mathrm{AD}=$ Alzheimer's disease; CNS = central nervous system; $\mathrm{SD}=$ standard deviation.

* Comparison among groups (stable cognition, prodromal, and $A D$ ) was performed using the Kruskal-Wallis test for continuous variables and Fisher's exact test for categorical variables.

$n=90$ because two cases were classified as unspecified intellectual disability (ICD-10 code F79) and were excluded: one from the AD group and one from the prodromal dementia group. 
Table 2 Cross-tabulation of the CAMDEX-DS and gold standard diagnoses

\begin{tabular}{|c|c|c|c|c|}
\hline \multirow[b]{2}{*}{ Variable/CAMDEX-DS diagnosis } & \multicolumn{3}{|c|}{ Gold standard diagnosis } & \multirow[b]{2}{*}{ Total } \\
\hline & $A D$ & Prodromal dementia & Stable cognition & \\
\hline \multicolumn{5}{|l|}{ Sample as a whole (n) } \\
\hline$A D$ & 11 & 2 & 0 & 13 \\
\hline Prodromal dementia & 0 & 16 & 1 & 17 \\
\hline Stable cognition & 0 & 0 & 62 & 62 \\
\hline Total & 11 & 18 & 63 & 92 \\
\hline \multicolumn{5}{|l|}{ Diagnosis (\%) } \\
\hline$A D$ & 100.0 & 11.1 & 0.0 & 14.1 \\
\hline Prodromal dementia & 0.0 & 88.9 & 1.6 & 18.5 \\
\hline Stable cognition & 0.0 & 0.0 & 98.4 & 67.4 \\
\hline Total & 100.0 & 100.0 & 100.0 & 100.0 \\
\hline \multicolumn{5}{|l|}{ Total (\%) } \\
\hline$A D$ & 11.9 & 2.2 & 0.0 & 14.1 \\
\hline Prodromal dementia & 0.0 & 17.4 & 1.1 & 18.5 \\
\hline Stable cognition & 0.0 & 0.0 & 67.4 & 67.4 \\
\hline Total & 11.9 & 19.6 & 68.5 & 100.0 \\
\hline
\end{tabular}

$\mathrm{AD}=$ Alzheimer disease; CAMDEX-DS = Cambridge Examination for Mental Disorders of Older People with Down syndrome and Others with Intellectual Disabilities.

individuals diagnosed with $A D$ declined by $>5.8$ points. The $95 \% \mathrm{Cl}$ for cognitive decline did not intersect between the stable cognition and AD groups $(95 \% \mathrm{Cl}-2.25$ to 4.07 vs. -39.39 to -4.61 ), which indicates that there is a distinction between them. This was not the case for the prodromal dementia group $(95 \% \mathrm{Cl}-7.15$ to 2.48$)$, indicating that it is an intermediate group between the stable cognition and $A D$ groups. For the $A D$ and prodromal groups together, the $95 \% \mathrm{Cl}$ for cognitive decline over the three years ranged from -17.38 to -0.39 . The probability of $a>5.8$ point decline in CAMCOG score was $83 \%$ for those diagnosed with $A D$ or prodromal dementia (OR = $12.5,95 \% \mathrm{Cl} 1.08$ to 143.43$)$.

\section{Inter-rater reliability of the CAMCOG-DS}

For the inter-rater reliability analysis, we collected data on a subgroup of 20 participants, eight $(40 \%)$ of whom were male. The mean age was 44.80 years (SD 7.51 years; range, $32-60$ years). One (5\%) was diagnosed with $A D$ and six $(30 \%)$ with prodromal dementia. Ten $(50 \%)$ had mild intellectual disability, nine $(45 \%)$ had moderate intellectual disability, and one $(5 \%)$ was classified as having unspecified intellectual disability due to cognitive decline without a prior classification. Although the interrater agreement was excellent $(\kappa>0.90, p<0.001)$ for most $(87 \%)$ of the CAMCOG-DS items, it was lower $(\kappa=$ $0.80-0.90, p<0.001)$ for three items $(6 \%)$. Table 3 presents items for which the kappa statistic was $<0.8$.

\section{Discussion}

Diagnosing dementia in individuals with a history of cognitive impairment, such as people with DS, continues to be a challenge due to the lowered baseline functioning and pre-existing abnormalities in brain development. In this study, we have demonstrated that the Portugueselanguage version of the CAMDEX-DS, adapted for use in Brazil, is highly accurate for diagnosing dementia and identifying cognitive and functional prodromal decline in individuals with DS. The CAMDEX-DS could detect nearly all of the cases of prodromal dementia and $A D$ that were diagnosed with the gold standard method, providing a faster and standardized interview. Of the participants testing positive for AD on the CAMDEX-DS, $84 \%$ were considered true positive, as were $94 \%$ of those testing positive for prodromal dementia. The ability of the CAMDEX-DS to refute other diagnoses was also good. The level of agreement between the CAMDEX-DS-based and gold standard diagnoses was similar to that found in the validation study conducted in Spain. ${ }^{21}$ The majority of the CAMCOG-DS items presented excellent inter-rater reliability $(\kappa>0.8)$.

We found that age had a strong influence on the selected variables, which can be explained by the known associations among age, cognitive decline, and $\mathrm{AD} .^{38}$ The stable cognition group was considerably younger than the prodromal dementia group, just as the prodromal dementia group was younger than the AD group. Prodromal dementia appeared as a transitional stage in this population, as is the case for mild cognitive impairment in the general population. ${ }^{39}$ The key difference is that the age of onset for cognitive decline and dementia in this population is nearly 20 years earlier than that reported for the general population, which corroborates the findings of previous studies showing that individuals with DS present early aging. ${ }^{40}$

Despite the excellent validity and reliability observed for the CAMDEX-DS, the importance of training in its application and interpretation should be stressed. Although the CAMDEX-DS guides the investigation to elucidate aspects necessary for an adequate evaluation, a CAMDEX-DSbased diagnosis still relies on clinical judgement. Just as with the use of the CAMDEX in the general population, there is no formula or cutoff score that directly indicates a specific diagnosis; knowledge in the area and a clinical appraisal are of fundamental importance. Nevertheless, at the end of the questionnaires, the CAMDEX provides a guide for clinical diagnosis, with information on universally 
Table 3 Inter-rater reliability study: Cambridge Cognitive Examination adapted for individuals with Down Syndrome (CAMCOG-DS) items with a kappa statistic $<0.8$

\begin{tabular}{|c|c|c|c|}
\hline CAMCOG-DS item/version & Content & kappa & p-value \\
\hline $\begin{array}{l}187 \\
\text { Original }\end{array}$ & $\begin{array}{l}\text { Language-Definition } \\
\text { What is a bridge? } \\
\text { A general (abstract) definition scores } 2 \text { and a specific or limited definition scores } 1 . \\
\qquad \sqrt{ } \text { Goes across river (2) } \\
\sqrt{ } \text { Cross the bridge (1) } \\
\sqrt{ } \text { Incorrect }(0)\end{array}$ & 0.583 & 0.002 \\
\hline Brazilian Portuguese & $\begin{array}{l}\text { O que é uma ponte? } \\
\text { Definição geral (abstrata) pontua } 2 \text { e uma definição limitada pontua } 1 . \\
\qquad \sqrt{ } \text { Atravessa um rio (2) } \\
\sqrt{ } \text { Atravessa a ponte (1) } \\
\sqrt{ } \quad \text { Incorreto (0) }\end{array}$ & & \\
\hline $\begin{array}{l}202 \\
\text { Original }\end{array}$ & $\begin{array}{l}\text { Praxis-Copy } \\
\text { Copy this picture (3D house). } \\
\text { Tick each component successfully completed and enter number under Total. } \\
\sqrt{ } \text { Outline of house } \\
\sqrt{ } \text { Windows, doors, and chimney in correct position } \\
\sqrt{ } \text { 3D representation }\end{array}$ & 0.773 & 0 \\
\hline Brazilian Portuguese & $\begin{array}{l}\text { Copie esta forma (casa). } \\
\text { Marque cada componente completado com sucesso e anote o número de } \\
\text { componentes no Total. } \\
\qquad \sqrt{ } \text { Perfil de casa } \\
\qquad \sqrt{ } \text { Janela, porta e chaminé nas posições certas } \\
\sqrt{ } \text { Representação } 3 D\end{array}$ & & \\
\hline $\begin{array}{l}216 \\
\text { Original }\end{array}$ & $\begin{array}{l}\text { Visual Perception } \\
\text { Who is this? (Queen/Pope, Archbishop, Bishop) } \\
\text { Score as correct if picture is recognized. } \\
\text { Correct name is not required, but record any answer that does not correspond } \\
\text { exactly to the examples given. }\end{array}$ & 0.615 & 0.032 \\
\hline Brazilian Portuguese & $\begin{array}{l}\text { Quem é este? (Pelé/Papa, Bispo) } \\
\text { Pontue como correto se a figura for reconhecida. } \\
\text { O nome correto não é requerido, mas registre qualquer resposta que não } \\
\text { corresponda exatamente aos exemplos dados. }\end{array}$ & & \\
\hline
\end{tabular}

accepted diagnostic criteria and guidelines for classifying the severity of dementia, thus offering support for this process. It is also of note that a CAMDEX evaluation places great emphasis on the information provided by the informant, thus requiring this person to have known the individual for quite some time, preferably having seen him/her quite frequently. Our finding that the number of primary caregivers who were not the parents tended to increase in parallel with an increase in the degree of dementia is probably attributable to the comparable relationship between the age of the participants and their cognitive decline: as individuals with DS age, their parents are more likely to die or become unable to provide care. This underscores the need to adapt care and public policies targeting this population in developing countries such as Brazil.

Our study has some limitations that should be considered. First and foremost is the lack of a validated instrument for diagnosing $A D$ in individuals with $D S$ in Brazil to use as a gold standard. However, to our knowledge, this is the first study attempting to determine the validity and reliability of a specific instrument for $A D$ in individuals with DS in Brazil. We attempted to reduce this gap by using internationally recognized criteria adapted for this population, ${ }^{30}$ as well as by determining its validity as measured against the cognitive decline observed in a subsample. We attempted to conduct an accurate investigation of all areas known to deteriorate in adults with DS and included instruments that have previously shown good applicability. ${ }^{28}$ Another limitation of our study is that both psychiatrist raters received the same training regarding intellectual disability and aspects related to aging in DS. Although we consider this training essential for both assessments, it could have been at least partially responsible for the high agreement rates. We believe that both raters had the knowledge necessary to make an accurate clinical evaluation, despite using different instruments for data collection and different diagnostic guidelines. Another limitation is that sedentary lifestyle, intellectual disability, the use of medication affecting the central nervous system, and a family history of $A D$ all showed significant differences among groups. Our cross-sectional study design prevented us from distinguishing the nature of those associations. For example, it is possible that the participants with prodromal dementia or AD became sedentary due to a functional decline. The degree of intellectual disability could be related to the level of cognitive reserve, as well as our inability to determine whether such deficits were associated with psychiatric symptoms. The use of medication that affects the central nervous system might be due to treatment for neuropsychiatric 
symptoms related to $A D$. Data in the literature suggest that a family history of $A D$ is a risk factor for developing the disease in the general population. ${ }^{41}$ However, in our sample, the appearance of cognitive decline symptoms might have focused more attention on family history. Furthermore, as with any other cognitive test applied in this population, the CAMCOG-DS has limited diagnostic value in a single evaluation. Without baseline measurements, it is impossible to determine to what extent cognitive malfunction is a consequence of a previous deficit or of another disorder that may affect cognitive ability, which thus might not necessarily be a decline. Nevertheless, a cognitive decline over time provides a useful complement to the diagnostic and support process, as evidenced in our longitudinal comparison, despite the small sample size. In addition, although most CAMCOG-DS items presented excellent inter-rater agreement, three items in particular were more difficult to score, perhaps because they presented more abstract concepts. A more detailed definition of the scores may help improve the evaluation of these items. The small number of participants in our longitudinal analysis of objective cognitive decline is another limitation of our study. Further studies are needed to explore these questions.

To our knowledge, this is the first study to validate an instrument for detecting $A D$ and cognitive decline in individuals with DS in Brazil. Given the challenges of early detection of neurodegenerative diseases in individuals with DS, there is a need for an assessment instrument that contemplates the specificities of the aging process in this population. The CAMDEX-DS appears to be a valid and reliable instrument for facilitating the early identification of cognitive and functional changes, as well as for refining the diagnosis of individuals with DS in Brazil, thus allowing care to be adapted to their demands and supporting further research in this area.

\section{Acknowledgements}

We dedicate this article to Prof. Cassio Machado de Campos Bottino (in memoriam), who closely supervised the study from beginning to end. We would like to thank all the participants and their families; APAESP and ADID; and the PROTER Research Group. We are also grateful to Juliana Emy Yokomizo and Sharon Sanz Simon, for analysis of comprehension and equivalence; Juliana Mascarenhas Fonseca, for back-translation; Prof. Rita Ferreira de Cassia Alves, for her suggestions about the adaptation; and Debora Boschetti, for her help with the pilot study. This study was supported by the Fundação de Amparo à Pesquisa do Estado de São Paulo (FAPESP; grants 2013/11571-9 and 2016/22123-5).

\section{Disclosure}

The authors report no conflicts of interest.

\section{References}

1 Lejeune J, Gautier M, Turpin R. [Study of somatic chromosomes from 9 mongoloid children]. C R Hebd Seances Acad Sci. 1959;248: 1721-2.
2 Gili JA, Poletta FA, Gimenez LG, Pawluk MS, Campana H, Castilla $\mathrm{EE}$, et al. Descriptive analysis of high birth prevalence rate geographical clusters of congenital anomalies in South America. Birth Defects Res A Clin Mol Teratol. 2016;106:257-66.

3 Parker SE, Mai CT, Canfield MA, Rickard R, Wang Y, Meyer RE, et al. Updated national birth prevalence estimates for selected birth defects in the United States, 2004-2006. Birth Defects Res A Clin Mol Teratol. 2010;88:1008-16.

$4 \mathrm{Wu}$ J, Morris JK. Trends in maternal age distribution and the live birth prevalence of Down's syndrome in England and Wales: 1938-2010. Eur J Hum Genet. 2013;21:943-7.

5 Wisniewski KE, Wisniewski HM, Wen GY. Occurrence of neuropathological changes and dementia of Alzheimer's disease in Down's syndrome. Ann Neurol. 1985;17:278-82.

6 Kimura R, Kamino K, Yamamoto M, Nuripa A, Kida T, Kazui H, et al. The DYRK1A gene, encoded in chromosome 21 Down syndrome critical region, bridges between beta-amyloid production and tau phosphorylation in Alzheimer disease. Hum Mol Genet. 2007;16:15-23.

7 Cole JH, Annus T, Wilson LR, Remtulla R, Hong YT, Fryer TD, et al. Brain-predicted age in Down syndrome is associated with beta amyloid deposition and cognitive decline. Neurobiol Aging. 2017;56:41-9.

8 Annus T, Wilson LR, Hong YT, Acosta-Cabronero J, Fryer TD, Cardenas-Blanco A, et al. The pattern of amyloid accumulation in the brains of adults with Down syndrome. Alzheimers Dement. 2016;12: 538-45.

9 Neale N, Padilla C, Fonseca LM, Holland T, Zaman S. Neuroimaging and other modalities to assess Alzheimer's disease in Down syndrome. Neuroimage Clin. 2017;17:263-71.

10 Fonseca LM, Yokomizo JE, Bottino CM, Fuentes D. Frontal lobe degeneration in adults with Down syndrome and Alzheimer's disease: a review. Dement Geriatr Cogn Disord. 2016;41:123-36.

11 Ball SL, Holland AJ, Huppert FA, Treppner P, Watson P, Hon J. The modified CAMDEX informant interview is a valid and reliable tool for use in the diagnosis of dementia in adults with Down's syndrome. J Intellect Disabil Res. 2004;48:611-20.

12 Deb S, Hare M, Prior L, Bhaumik S. Dementia screening questionnaire for individuals with intellectual disabilities. $\mathrm{Br} J$ Psychiatry. 2007;190:440-4.

13 Evenhuis HM. Evaluation of a screening instrument for dementia in ageing mentally retarded persons. J Intellect Disabil Res. 1992;36: 337-47.

14 Prasher V, Farooq A, Holder R. The adaptive behaviour dementia questionnaire (ABDQ): screening questionnaire for dementia in Alzheimer's disease in adults with Down syndrome. Res Dev Disabil. 2004;25:385-97.

15 Fonseca LM, Ball SL, Holland AJ. The Cambridge Examination for Mental Disorders of Older People with Down's Syndrome and Others with Intellectual Disabilities (CAMDEX-DS). In: Prasher VP, editor. Neuropsychological assessment of dementia in Down syndrome and intellectual disabilities. New York: Springer; 2018. p. 123-44.

16 Roth M, Tym E, Mountjoy CQ, Huppert FA, Hendrie H, Verma S, et al. CAMDEX. A standardised instrument for the diagnosis of mental disorder in the elderly with special reference to the early detection of dementia. Br J Psychiatry. 1986;149:698-709.

17 Bottino CMC, Stoppe A, Scalco AZ, Ferreira RCR, Hototian SR, Scalco MZ. Validade e confiabilidade da versão brasileira do CAMDEX. Arq Neuropsuquiatr. 2001;59:S20.

18 Aprahamian I, Martinelli JE, Cecato J, Yassuda MS. Screening for Alzheimer's disease among illiterate elderly: accuracy analysis for multiple instruments. J Alzheimers Dis. 2011;26:221-9.

19 Azevedo D, Tatsch M, Hototian SR, Bazzarella MC, Castro CC, Bottino CM. Proton spectroscopy in Alzheimer's disease and cognitive impairment no dementia: a community-based study. Dement Geriatr Cogn Disord. 2008;25:491-500.

20 Forlenza OV, Wacker P, Nunes PV, Yacubian J, Castro CC, Otaduy MC, et al. Reduced phospholipid breakdown in Alzheimer's brains: a 31P spectroscopy study. Psychopharmacology (Berl). 2005;180: 359-65.

21 Esteba-Castillo S, Dalmau-Bueno A, Ribas-Vidal N, Vila-Alsina M, Novell-Alsina R, Garcia-Alba J. [Adaptation and validation of CAMDEX-DS (Cambridge Examination for Mental Disorders of Older People with Down's Syndrome and others with intellectual disabilities) in Spanish population with intellectual disabilities]. Rev Neurol. 2013;57:337-46. 
22 Landt J, Ball SL, Holland AJ, Hon J, Owen A, Treppner P, et al. Agerelated changes in plasma dehydroepiandrosterone levels in adults with Down's syndrome and the risk of dementia. J Neuroendocrinol. 2011;23:450-5.

23 Ball SL, Holland AJ, Treppner P, Watson PC, Huppert FA. Executive dysfunction and its association with personality and behaviour changes in the development of Alzheimer's disease in adults with Down syndrome and mild to moderate learning disabilities. $\mathrm{Br} \mathrm{J}$ Clin Psychol. 2008;47:1-29.

24 Hon J, Huppert FA, Holland AJ, Watson P. Neuropsychological assessment of older adults with Down's syndrome: an epidemiological study using the Cambridge cognitive examination (CAMCOG). Br J Clin Psychol. 1999;38:155-65.

25 Annus T, Wilson LR, Acosta-Cabronero J, Cardenas-Blanco A, Hong YT, Fryer TD, et al. The Down syndrome brain in the presence and absence of fibrillar beta-amyloidosis. Neurobiol Aging. 2017;53: 11-9.

26 Beacher F, Simmons A, Daly E, Prasher V, Adams C, Margallo-Lana $\mathrm{ML}$, et al. Hippocampal myo-inositol and cognitive ability in adults with Down syndrome: an in vivo proton magnetic resonance spectroscopy study. Arch Gen Psychiatry. 2005;62:1360-5.

27 McPaul A, Walker B, Law J, McKenzie K. An exploratory study investigating how adults with intellectual disabilities perform on the visual association test (VAT). J Appl Res Intellect Disabil. 2017;30: 824-9.

28 Fonseca LM, de Oliveira MC, de Figueiredo Ferreira Guilhoto LM, Cavalheiro EA, Bottino CM. Bereavement and behavioral changes as risk factors for cognitive decline in adults with Down syndrome. Neuropsychiatric Dis Treat. 2014;10:2209-19.

29 Fonseca LM, Mattar GP, Haddad GG, Simon SS, Yokomizo JE, Fonseca JM, et al. CAMDEX-DS: Exame CAMBRIDGE para transtornos mentais em adultos com síndrome de Down e outros com deficiência intelectual (tradução e adaptação). São Paulo: PROTER, Departamento de Psiquiatria do Hospital das Clínicas da Faculdade de Medicina da USP; 2016.

30 Fletcher R, Loschen E, Stavrakaki C, First M. Diagnostic manualintellectual disability: a text book of diagnosis of mental disorder in persons with intellectual disability. New York: National Association for the Dually Diagnosed NAAD; 2007.
31 American Psychiatric Association. Diagnostic and Statistical Manual of Mental Disorders, Fifth Edition (DSM-5). Arlington: American Psychiatric Publishing; 2013.

32 World Health Organization (WHO). ICD10 International Statistical Classification of Diseases and Related Health Problems, 10th revision [Internet]. 1992 [cited 2018 May 21]. www.who.int/classifications/icd/ ICD10Volume2_en_2010.pdf

33 Jorm AF, Jacomb PA. The informant questionnaire on cognitive decline in the elderly (IQCODE): socio-demographic correlates, reliability, validity and some norms. Psychol Med. 1989;19:1015-22.

34 Cummings JL, Mega M, Gray K, Rosenberg-Thompson S, Carusi DA, Gornbein J. The neuropsychiatric inventory: comprehensive assessment of psychopathology in dementia. Neurology. 1994;44:2308-14.

35 Grace J, Malloy PF; Psychological Assessment Resources Inc. Frontal systems behavior scale (FrSBe): professional manual. Lutz: Psychological Assessment Resources; 2001.

36 Wechsler D. Manual for the Wechsler adult intelligence scale revised. New York: Psychological Corporation; 1981.

37 Harris PA, Taylor R, Thielke R, Payne J, Gonzalez N, Conde JG. Research electronic data capture (REDCap)--a metadata-driven methodology and workflow process for providing translational research informatics support. J Biomed Inform. 2009;42:377-81.

38 Lipnicki DM, Crawford JD, Dutta R, Thalamuthu A, Kochan NA Andrews $\mathrm{G}$, et al. Age-related cognitive decline and associations with sex, education and apolipoprotein $E$ genotype across ethnocultural groups and geographic regions: a collaborative cohort study. PLoS Med. 2017;14:e1002261.

39 Petersen RC, Caracciolo B, Brayne C, Gauthier S, Jelic V, Fratiglioni L. Mild cognitive impairment: a concept in evolution. J Intern Med. 2014;275:214-28.

40 Zigman WB. Atypical aging in Down syndrome. Dev Disabil Res Rev. 2013;18:51-67.

41 Vardarajan BN, Faber KM, Bird TD, Bennett DA, Rosenberg R, Boeve BF, et al. Age-specific incidence rates for dementia and Alzheimer disease in NIA-LOAD/NCRAD and EFIGA families: National Institute on Aging Genetics Initiative for Late-Onset Alzheimer Disease/National Cell Repository for Alzheimer Disease (NIA-LOAD/ NCRAD) and Estudio Familiar de Influencia Genetica en Alzheimer (EFIGA). JAMA Neurol. 2014;71:315-23. 